\title{
Efecto del almacenamiento ex situ de semillas y de condiciones lumínicas sobre la tasa de crecimiento de plántulas de Crescentia alata (Bignoniaceae)
}

\author{
Kimberly Valverde-Rodríguez*, Carlos O. Morales \& Elmer G. García \\ Escuela de Biología, Universidad de Costa Rica, San José, Costa Rica; kian124@hotmail.com, \\ carlos.moralessanchez@ucr.ac.cr,elmer.garcia@ucr.ac.cr \\ * Correspondencia
}

Recibido 08-XI-2017. Corregido 25-II-2019. Aceptado 26-III-2019.

\begin{abstract}
Effect of seed storage and light conditions on the growth rate of Crescentia alata (Bignoniaceae) seedlings. The dry tropical forest tree Crescentia alata is a cultural and economical resource, but efforts to establish plantations, which could satisfy commercial production and avoid impact on natural populations, have been unsuccessful. So there is a need to generate biological information on this species for obtaining plants in greenhouses. The aim of this work was to evaluate the vigor and growth rate of $C$. alata seedlings born from seeds that were stored at different periods and temperatures, and to determine the effect of light intensity on the seedlings. Fruits were collected in Liberia (Guanacaste, Costa Rica) and seeds stored for $0,4,8$, and 14 months at $5{ }^{\circ} \mathrm{C}$, $15^{\circ} \mathrm{C}$, and ambient temperature $\left(22-24^{\circ} \mathrm{C}\right)$. Seedlings from seeds stored for $0,4,8$ and 14 months were grown to evaluate growth after 8 days, 2 months, and 16 months, and in two different light conditions. Morphology of 8-day-seedlings changed according to storage time. Principal component analysis of 2-month evaluation indicates that the most significant variables were total dry biomass, dry biomass of leaves, root-shoot, stem, and root, while for the analysis of 16-month evaluation these variables were dry biomass of root, root-shoot, and leaves, also leaf number, and shoot length. Specific leaf area of 16-month plants from seeds stored for 14 months did not change with storage temperature. In addition, two different light conditions influence seedling height, stem diameter or leaf number. Seed storage at $5{ }^{\circ} \mathrm{C}$ and $15^{\circ} \mathrm{C}$ favored development of seedling cotyledons, and length of both root and hypocotyl. Two month-seedlings from $0 \mathrm{M}$ and $8 \mathrm{M}$ allocated most biomass to roots and less to stems, enhancing this way water absorption. Sixteen-month-plants from non-stored seeds developed the highest leaf numbers, and those plants from $8 \mathrm{M}$ seeds at $5{ }^{\circ} \mathrm{C}$ and $15^{\circ} \mathrm{C}$ showed shorter stems. Seeds stored up to 14 months kept viable, becoming healthy seedlings. We recommend that future researchers evaluate seed viability at different drying temperatures and more contrasting light levels.
\end{abstract}

Key words: Jicaro tree; biomass allocation; seedling development; viability; vigor; seed storage; Costa Rica.

Valverde-Rodríguez, K., Morales, C. O. \& García, E. G. (2019). Efecto del almacenamiento ex situ de semillas y de condiciones lumínicas sobre la tasa de crecimiento de plántulas de Crescentia alata (Bignoniaceae). Revista de Biología Tropical, 67(2) Suplemento, S132-S148.

La regeneración de bosques y el reclutamiento de nuevas plantas son importantes para conservar las especies y mantener la dinámica natural (Galindo-González, 1998; Mostacedo, Pereira, \& Fredericksen, 2001). Sin embargo, en ocasiones no se restablecen algunas especies por razones antropogénicas o naturales.
Por esto, es importante estudiar el manejo de semillas, la producción de plantas en vivero y el establecimiento de plantaciones a partir de condiciones controladas, que colaboren con la restauración (González, 1991).

Muchas semillas de interés comercial se almacenan para conservar recursos 
fitogenéticos (Wyse \& Dickie, 2018). En esas condiciones se hacen pruebas de viabilidad y vigor, porque ciertas condiciones de recolección, almacenamiento y el tipo de semilla (ortodoxa o recalcitrante) pueden reducir la calidad de este propágulo (Hong \& Ellis, 1996; Salinas, Yoldjian, Craviotto, \& Bisaro, 2001; De Viana, Mosiaro, \& Morandini, 2009). La viabilidad se define como la capacidad germinativa en condiciones adecuadas de temperatura, agua, oxígeno y luz, después de un período (Doria, 2010; Navarro, Febles, \& Torres, 2012), y el vigor es la suma total de propiedades de las semillas que determinan el nivel de actividad y la capacidad de germinación, reflejados en cambios bioquímicos, tasa y uniformidad de germinación y crecimiento de plántulas (Barboza \& Herrera, 1990; Navarro et al., 2012). Sin embargo, el crecimiento de una planta no está determinado solo por la calidad de la semilla, sino también por la interacción de fotosíntesis, transporte a larga distancia, respiración, relaciones hídricas, nutrición mineral e interacción entre genotipo y ambiente. Todo esto se reflejará en la masa seca, el volumen, la longitud o el área de la planta (Lambers, Chapin, \& Pons, 2008).

El deterioro de la calidad de la semilla se cuantifica con la reducción de vigor, de germinación y de producción de plántulas normales. Los estudios para detectar ese deterioro ayudan a solucionar problemas en la industria semillera (Salinas et al., 2001; Navarro et al., 2012), pero la mayoría de investigaciones sobre medición del vigor se enfatizan en especies hortícolas, mientras los trabajos sobre crecimiento de árboles y arbustos tropicales son muy escasos (Navarro et al., 2012). Un ejemplo es el género Crescentia (Bignoniaceae), que consta de árboles de interés cultural y económico en Mesoamérica, especialmente en El Salvador y Nicaragua (Gentry, 1980; Corrales et al., 2017), dada la gran variedad de usos registrados, algunos desde tiempos prehispánicos, como la elaboración de utensilios de cocina y artesanías, la extracción de madera, carbón y tinte, la preparación de bebidas (alcohólicas, horchata y "leche vegetal"), reposterías, caramelos y alimento para animales de engorde o producción de leche (Standley, 1928; Nellis, 1997; Figueroa \& Bressani, 2000; Salazar \& Soihet, 2001; Zamora et al., 2001; Cordero \& Boshier, 2003; Solares, 2004).

Crescentia alata Kunth es un árbol caulifloro y alcanza $10 \mathrm{~m}$ de altura; posee hojas trifolioladas con pecíolo alado y los foliolos forman una cruz; las flores son verde-amarillentas con tonalidad amarilla a rojiza, de antesis nocturna y son polinizadas por murciélagos (Quesada-Monge \& Fernández-Vega, 2005). Los frutos son esféricos, con pericarpo lignificado y liso, poseen nectarios en estadios tempranos de desarrollo y una pulpa abundante rodea las semillas, que son pequeñas, delgadas, con testa color café y de tipo oleaginoso por el alto contenido de lípidos y proteínas (Elias \& Prance, 1978; Gentry, 1980; Snarkis, 1989; Cordero \& Boshier, 2003; Vargas, 2011; Corrales et al., 2017). Se ha observado que los caballos dispersan las semillas y, además, esta especie ha sido cultivada (Janzen, 1982). Habita principalmente en la vertiente pacífica desde México hasta Guanacaste en Costa Rica; es común en potreros, áreas abiertas y bordes de bosques secos, subperennifolios y caducifolios (Gentry, 1980; Janzen, 1982; Solares, 2004). En Costa Rica $C$. alata habita en el bosque tropical seco, que cubre solamente $7.3 \%$ del territorio nacional (Alfaro, Alvarado, \& Chaverri, 2001).

Con semillas de $C$. alata obtenidas en Honduras, se estudió en Malawi la posibilidad de establecer plantaciones de árboles multipropósitos. Allá germinó el $93 \%$ de las semillas en 21 días sin tratamiento pregerminativo, mientras al aplicar ácido sulfúrico no ocurrió germinación (Ngulube, 1989). En Guatemala, Honduras y Nicaragua hubo algunos intentos fallidos para establecer plantaciones de $C$. alata (Cordero \& Boshier, 2003). En sistemas silvopastoriles de Nicaragua hay en promedio 350 árboles de C. alata por hectárea, que representan un alto potencial de producción comercial (Corrales et al., 2017). Según Solares (2004), en México esta especie tuvo un uso intensivo, pero en la actualidad el tamaño 
poblacional es bajo, entre dos y diez árboles por hectárea.

Semillas de C. alata de Guanacaste (Costa Rica) mantuvieron la viabilidad durante tres años, conservadas a $5{ }^{\circ} \mathrm{C}$ y $15{ }^{\circ} \mathrm{C}$, y posteriormente el 90 \% germinó (Valverde-Rodríguez, Morales \& García, 2019). Sin embargo, las condiciones de almacenamiento, como la temperatura y humedad de la semilla, están relacionadas con el vigor (Salinas et al., 2001). El objetivo de esta investigación fue evaluar la tasa de crecimiento de plantas de Crescentia alata a partir de semillas almacenadas en distintos períodos y a varias temperaturas, y el efecto de la intensidad de la luz sobre el crecimiento de las plántulas.

\section{MATERIALES Y MÉTODOS}

Los experimentos se hicieron en la Escuela de Biología y en el Centro de Investigaciones en Granos y Semillas (CIGRAS) de la Universidad de Costa Rica (San José, Costa Rica). Las semillas se obtuvieron de frutos enteros maduros y sin daños en la cáscara, recolectados de ca. 50 árboles seleccionados al azar en Liberia, Guanacaste, Costa Rica $\left(10^{\circ} 36^{\prime} \mathrm{N}\right.$, $85^{\circ} 31^{\prime} \mathrm{W}$ ), en febrero de 2013. Un espécimen de $C$. alata, testigo de esta investigación, se halla en el Herbario de la Universidad de Costa Rica (USJ-110912). Los frutos se despulparon manualmente. Las semillas fueron lavadas y secadas a la sombra durante una semana y con una evaluación física se descartaron semillas vanas, de menor tamaño que la mayoría y con daños mecánicos, como agujeros o fragmentación de la testa; entre las semillas sanas restantes se seleccionaron al azar las necesarias para los experimentos.

Las semillas se almacenaron durante 0,4 , 8 y 14 meses, a $5{ }^{\circ} \mathrm{C}, 15{ }^{\circ} \mathrm{C}$ y a temperatura ambiente (promedio ca. $22-24{ }^{\circ} \mathrm{C}$ en un invernadero). Se embebieron durante 12 horas para evaluar la germinación, con 500 semillas por tratamiento, y se colocaron en cajas plásticas de $21 \mathrm{~cm}$ de largo, $14 \mathrm{~cm}$ de ancho y $7 \mathrm{~cm}$ de alto, con el fondo cubierto con turba para germinación marca Fafard, en una cámara de ambiente controlado Hoffman Manufacturing Inc., a $30^{\circ} \mathrm{C}$ durante el día y $25^{\circ} \mathrm{C}$ de noche, con fotoperíodo de 12 horas y humedad relativa de 98-100 \%. Del total de plántulas obtenidas, se seleccionaron al azar para hacer las siguientes mediciones.

Mediciones de plántulas: Ocho días después de colocar las semillas en turba, en cada período de almacenamiento $(0,4,8$ y 14 meses), se seleccionaron 20 plántulas de cada temperatura $\left(5{ }^{\circ} \mathrm{C}, 15{ }^{\circ} \mathrm{C}\right.$ y ambiente $)$ para medir con un calibrador Vernier $( \pm 0.05 \mathrm{~mm})$ el ancho y largo de un cotiledón, la longitud de la radícula, del hipocótilo y del epicótilo. Para cuantificar si el almacenamiento causa cambios morfométricos en las plántulas se realizó un análisis de varianza múltiple (ANDEVAM) con variables no correlacionadas $(\mathrm{P}<0.05)$ : ancho del cotiledón, longitud de radícula, del hipocótilo y del epicótilo, según el tiempo y la temperatura de almacenamiento. Además, se calculó el coeficiente no paramétrico de correlación de Spearman por temperatura $(\mathrm{n}=$ 10) entre longitud de radícula y contenido de humedad $(\mathrm{CH})$ de semillas almacenadas a 0,4 , 8 y 14 meses a temperatura ambiente, $5{ }^{\circ} \mathrm{C}$ y $15^{\circ} \mathrm{C}$, el $\mathrm{CH}$ con 10 repeticiones de 10 semillas cada una. Los datos de $\mathrm{CH}$ proceden de Valverde-Rodríguez et al. (2019) (Cuadro 1), cuantificados con la fórmula de la Asociación Internacional de Pruebas de Semillas (ISTA, 2016), Contenido de humedad $=[$ (Masa fresca - Masa seca)/Masa fresca]*100. Las semillas se dejaron en bolsas de papel en una secadora Sheldon Manufacturing Inc., modelo 14.5/89, a $80{ }^{\circ} \mathrm{C}$ durante 15 días.

En los siguientes experimentos de crecimiento, las plantas se sembraron en bolsas con suelo sin esterilizar del campus de la Universidad de Costa Rica en San José, y permanecieron en condiciones de invernadero, con temperatura promedio de 22 a $27^{\circ} \mathrm{C}$, fluctuante durante el día y la noche y según la época del año, con interceptación de luz de $100 \%$ y 277 $\mu \mathrm{mol} \mathrm{m} \mathrm{m}^{-2} \mathrm{~s}^{-1}$, riego una vez por semana. Se aplicó insecticida multiefecto marca Ever Green para eliminar plagas ocasionales. 
CUADRO 1

Contenido de humedad (promedio \pm desviación estándar) de semillas de Crescentia alata almacenadas a temperatura ambiente, $5{ }^{\circ} \mathrm{C}$ y $15^{\circ} \mathrm{C}$ por 14 meses, San José, Costa Rica

TABLE1

Moisture content (averages \pm standard deviation) of Crescentia alata seeds stored at ambient temperature, $5{ }^{\circ} \mathrm{C}$, and $15^{\circ} \mathrm{C}$ for 14 months, San José, Costa Rica

\begin{tabular}{cccc} 
Período & \multicolumn{3}{c}{ Temperatura } \\
& $5{ }^{\circ} \mathrm{C}$ & $15^{\circ} \mathrm{C}$ & Ambiente \\
0 & $9.53 \pm 0.38$ & $9.53 \pm 0.38$ & $9.53 \pm 0.38$ \\
4 & $8.87 \pm 0.34$ & $6.96 \pm 0.29$ & $8.37 \pm 0.36$ \\
8 & $8.56 \pm 1.42$ & $7.26 \pm 3.47$ & $8.03 \pm 0.87$ \\
14 & $9.07 \pm 0.21$ & $6.48 \pm 1.14$ & $9.34 \pm 1.08$ \\
\hline
\end{tabular}

Evaluación del crecimiento: Veinte plantas (distintas a las utilizadas en el experimento anterior) se trasplantaron del almácigo a bolsas ( $25 \mathrm{~cm}$ de alto, $10 \mathrm{~cm}$ ancho y $15 \mathrm{~cm}$ de largo) diez días después de germinadas por cada período de almacenamiento de semillas, representadas de la siguiente manera: $0,4,8$ y 14 meses, a $5{ }^{\circ} \mathrm{C}, 15^{\circ} \mathrm{C}$ y temperatura ambiente. Se hicieron dos evaluaciones: 2 y 16 meses de edad; cada una con 10 de las 20 plantas. Se midieron las siguientes variables: número de hojas, área foliar, longitud de raíz principal y de vástago, masa fresca y masa seca de raíz, vástago, tallo y hojas. Se calculó el área foliar con un medidor de área, marca LI-COR, modelo
Li-3100. Las estructuras vegetales se dejaron en bolsas de papel en una secadora Sheldon Manufacturing Inc. modelo $14.5 / 89$, a $70{ }^{\circ} \mathrm{C}$ durante ocho días para obtener masa seca constante. Se determinaron las masas frescas con una balanza analítica Sartorius AC 210S-MC1. El valor del área foliar y la masa de las hojas incluye los cotiledones, y la masa del vástago incluye hojas, cotiledones y tallo. A partir de las mediciones obtenidas en las evaluaciones se aplicaron las fórmulas (Cuadro 2) del contenido de humedad (ISTA, 2016) y de crecimiento y biomasa de Lambers et al. (2008).

Para cada evaluación se hizo análisis de componentes principales (ACP) con las

\section{CUADRO 2}

Fórmulas de variables con sus respectivas unidades utilizadas en el análisis de crecimiento de plantas de Crescentia alata en condiciones de invernadero, San José, Costa Rica

TABLE 2

Formulas of variables with their respective units used in the analysis of plant growth of Crescentia alata in greenhouse conditions, San José, Costa Rica

\begin{tabular}{ll}
\multicolumn{1}{c}{ Variables } & \multicolumn{1}{c}{ Fórmulas } \\
Tasa de crecimiento relativo & Biomasa húmeda final $(\mathrm{g})$ - Biomasa húmeda inicial $(\mathrm{g})$ - Tiempo (meses) \\
Tasa de elongación del tallo y raíz & Elongación final $(\mathrm{cm})$ - Elongación inicial $(\mathrm{cm})$ - Tiempo (meses) \\
Biomasa total húmeda & Masa fresca del vástago $(\mathrm{g})+$ Masa fresca de raíz $(\mathrm{g})$ \\
Biomasa total seca & Masa seca del vástago $(\mathrm{g})+$ Masa seca de raíz $(\mathrm{g})$ \\
Contenido de humedad: raíz, tallo y hojas & Biomasa húmeda $(\mathrm{g})$ - Biomasa seca $(\mathrm{g}) * 100$ - Biomasa húmeda $(\mathrm{g})$ \\
Contenido de humedad en la planta & Biomasa total húmeda $(\mathrm{g})$ - Biomasa total seca $(\mathrm{g}) * 100$ Biomasa total húmeda (g) \\
Índice de área foliar por planta & Área foliar total $\left(\mathrm{cm}^{2}\right)$ - Biomasa total seca de hojas $(\mathrm{g})$ \\
Biomasa asignada a: raíz, tallo y hojas & Biomasa seca $($ estructura $)(\mathrm{g})$ - Biomasa total seca $(\mathrm{g})$ \\
Relación entre raíz y vástago en la planta & Biomasa seca $($ raíz) $(\mathrm{g})$ - Biomasa seca (vástago) $(\mathrm{g})$ \\
Área foliar específica & Área foliar $\left(\mathrm{cm}^{2}\right)$ - Biomasa seca de hoja $(\mathrm{g})$ \\
\hline
\end{tabular}


variables: número de hojas, índice de área foliar, longitud de raíz y de vástago, biomasa total seca (BTS) y la biomasa seca (BS) en raíz, tallo, hojas y raíz-vástago, con el fin de conocer la tendencia de asignación de biomasa en las plantas según el almacenamiento (Apéndices 1 y 2). También se analizó con un ANDEVA de dos vías cada uno de los componentes, con el tiempo y la temperatura de almacenamiento como factores.

Se calcularon los promedios ( \pm desviaciones estándar) de las variables que contienen masa fresca en su fórmula, la tasa de crecimiento relativo (TCR), la tasa de elongación de tallo (TET) y de raíz (TER), según el período y la temperatura de almacenamiento. Para el cálculo de las tasas se usó como valor inicial la evaluación de 2 meses y como valor final la de 16 meses (Cuadro 2), analizadas con ANDEVA de dos vías y prueba de comparaciones múltiples Tukey-Kramer. Además, se calculó el área foliar específica (AFE) en plantas con 16 meses de edad obtenidas de semillas conservadas durante 14 meses a $5^{\circ} \mathrm{C}, 15^{\circ} \mathrm{C}$ y a temperatura ambiente, con 30 réplicas; esto se analizó con un ANDEVA de una vía y una prueba de comparaciones múltiples Tukey-Kramer.

Crecimiento según la luminosidad: Otras plantas se sometieron durante 14 meses a dos condiciones lumínicas, con 10 repeticiones. Se midieron altura y diámetro de tallo, se contó número de hojas y se observó tiempo de caída de cotiledones. Con un iluminómetro digital marca Kyoritsu, modelo 5201, la condición de mayor luminosidad (sol) fue de $277 \mu \mathrm{mol} \mathrm{m} \mathrm{m}^{-2}$ $\mathrm{s}^{-1}$ y la de menor luminosidad (sombra) 171 $\mu \mathrm{mol} \mathrm{m} \mathrm{m}^{-2} \mathrm{~s}^{-1}$. Se hicieron ANDEVA por cada variable (altura, diámetro y número de hojas) para ver el efecto de luminosidad y tiempo como mediciones repetidas.

Todos los análisis mencionados se hicieron con JMP ${ }^{\circledR}$ (SAS Institute Inc, 2012), Excel y Software R versión 3.1.1 (R Development Core Team, 2014).

\section{RESULTADOS}

A partir de un estudio previo (ValverdeRodríguez et al., 2019) con semillas de frutos recolectados en época seca en Guanacaste (Costa Rica), con turba de germinación como sustrato y remojo de 12 horas, sabemos que la germinación es epigea y la plántula fanerocotilar, las semillas germinaron entre 4 y 6 días posteriores al inicio de la imbibición y no requirieron de tratamiento pregerminativo. Además, el almacenamiento de 14 meses a temperatura ambiente redujo el porcentaje de germinación en $10 \%$ y retardó ca. 15 días el proceso de germinación, mientras al preservar las semillas a $5{ }^{\circ} \mathrm{C}$ y $15{ }^{\circ} \mathrm{C}$ la germinación se mantuvo constante. Así, el almacenamiento a bajas temperaturas puede mantener las semillas viables por más tiempo. Se observó lignificación de tallos en plantas con dos meses. Durante el crecimiento de las plantas aparecieron varias plagas: trips (Echinothrips caribbeanus) por un mes en hojas jóvenes y maduras, el hemíptero "mosca blanca" (familia Aleyrodidae) y hongos en las plantas de semillas conservadas 14 meses.

Mediciones de plántulas: La prueba ANDEVAM detectó diferencias en los tamaños de las plántulas según el almacenamiento de las semillas (Hotelling-Lawley $(\text { HTL })_{15,692}=0.64$, $\mathrm{P}<0.001$, Fig. 1), siendo también significativo el efecto del almacenamiento $\left(\mathrm{F}_{3,232}=0.58\right.$, $\mathrm{P}<0.001)$ y de la temperatura $\left(\mathrm{HTL}_{6,462}=\right.$ $0.02, \mathrm{P}=0.48)$ y no significativa su interacción $\left(\mathrm{HTL}_{6,462}=0.04, \mathrm{P}=0.161\right)$. El ancho del cotiledón aumentó a mayor almacenaje a $5{ }^{\circ} \mathrm{C}$; el largo del cotiledón aumentó con mayor tiempo de almacenamiento a temperatura ambiente, 5 ${ }^{\circ} \mathrm{C}$ y $15{ }^{\circ} \mathrm{C}$; la longitud de la radícula cambió a $15{ }^{\circ} \mathrm{C}$ y la del hipocótilo varió con las tres temperaturas del experimento, de manera que la longitud de la radícula y del hipocótilo creció al aumentar los períodos de almacenamiento (8 y 14 meses); a diferencia, la longitud del 

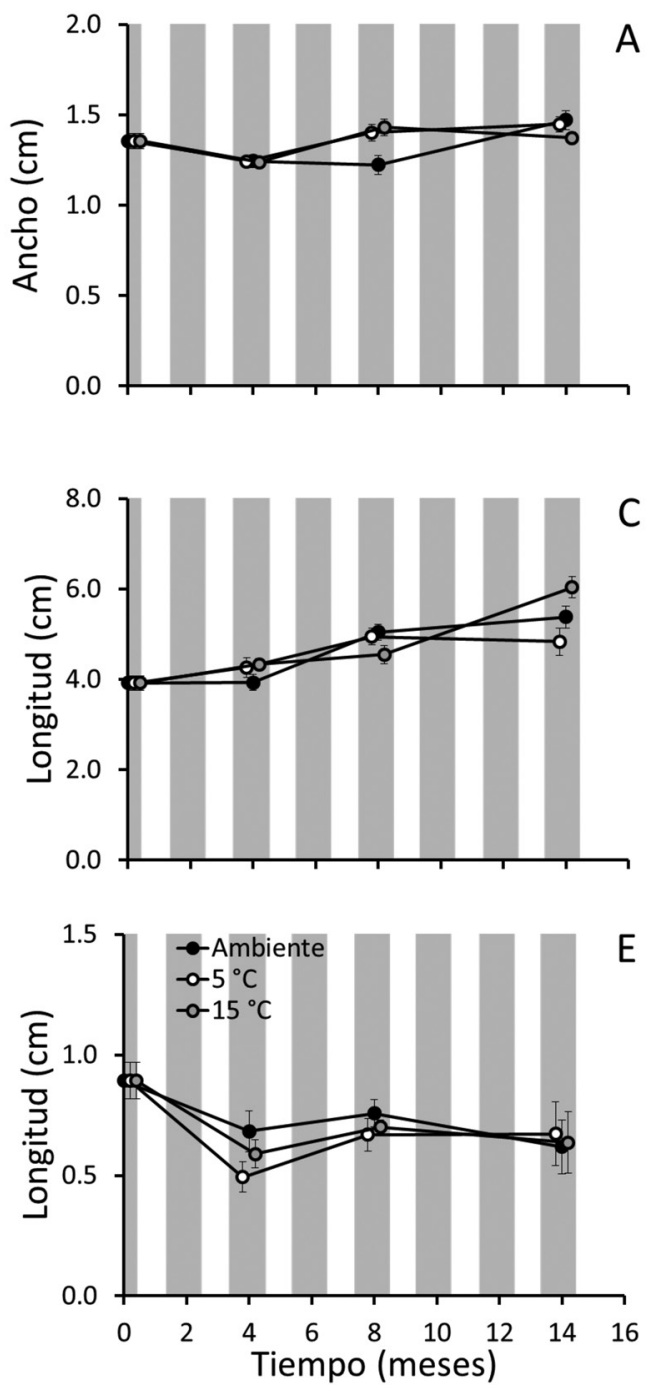

epicótilo no varió con el tiempo ni la temperatura de almacenamiento. Hubo correlación entre el $\mathrm{CH}$ y la longitud de la radícula a $5{ }^{\circ} \mathrm{C}$ $\left(r_{\mathrm{s}}=-0.39, \mathrm{n}=10, \mathrm{P}=0.012\right), \mathrm{a} 15^{\circ} \mathrm{C}\left(\mathrm{r}_{\mathrm{s}}=-0.44\right.$, $\mathrm{n}=10, \mathrm{P}=0.004)$ y a temperatura ambiente $\left(\mathrm{r}_{\mathrm{s}}=\right.$ $-0.35, \mathrm{n}=10, \mathrm{P}=0.025)$.

Evaluación del crecimiento: Los cotiledones permanecieron verdes entre 6 y 20 semanas, y una vez secos siguieron adheridos a las plantas hasta 64 semanas. Por lo general, en una semana las plántulas tuvieron hojas
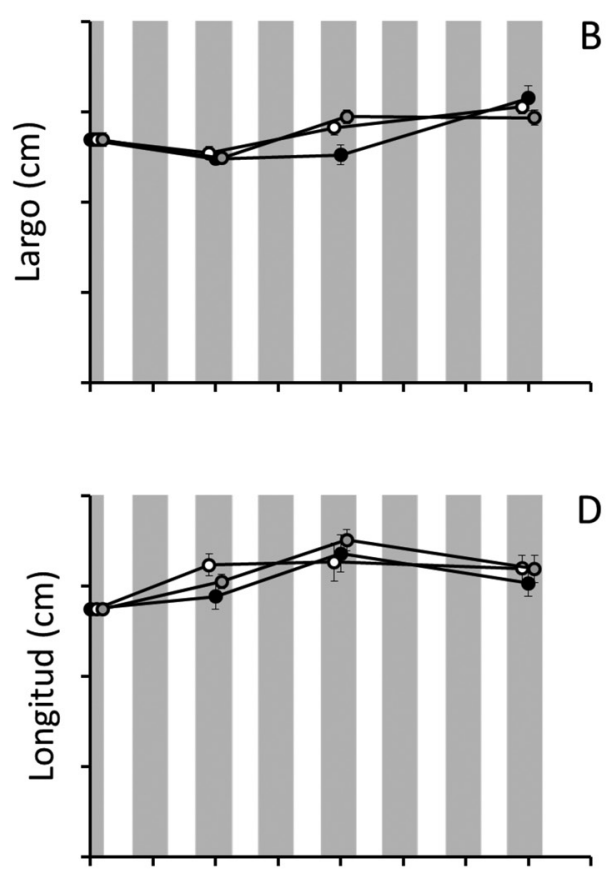

Fig. 1. Datos morfométricos (promedios \pm error estándar) en plántulas de Crescentia alata de ca. 2 días de edad obtenidas en pruebas de germinación, según períodos de almacenamiento $(0,4,8$ y 14 meses $)$ y temperaturas (5 ${ }^{\circ} \mathrm{C}, 15{ }^{\circ} \mathrm{C}$ y ambiente). A. ancho del cotiledón; B. longitud del cotiledón; C. longitud del hipocótilo; D. longitud de la radícula; E. longitud del epicótilo.

Fig. 1. Morphometric data (averages \pm standard error) in ca. 2-days old seedlings of Crescentia alata obtained in germination tests, related to storage periods $(0,4,8$, and 14 months) and temperatures $\left(5^{\circ} \mathrm{C}, 15^{\circ} \mathrm{C}\right.$, and ambient temperature). A. cotyledon width; B. cotyledon length; C. hypocotyl length; D. radicle length; E. epicotyl length.

desarrolladas; en 4 semanas tuvieron pequeñas hojas lineares $(<0.5 \mathrm{~cm}$ de largo $)$ y en 40 semanas desarrollaron hasta 50 de estas hojas. El Cuadro 3 muestra los promedios de las variables que incluyen masa fresca, según el período y la edad de la planta. Se observaron diferencias en las tasas de crecimiento relativo y de elongación de tallo y raíz (Cuadro 4); la TCR disminuyó al aumentar los meses de almacenamiento $\left(\mathrm{F}_{5,87}=5.66, \mathrm{P}=0.001\right)$, siendo menor en 8 y 14 meses (Tukey $=0.05$ ); 0 tuvo la mayor TET y 8 la menor $\left(\mathrm{F}_{5,87}=9.80\right.$, 

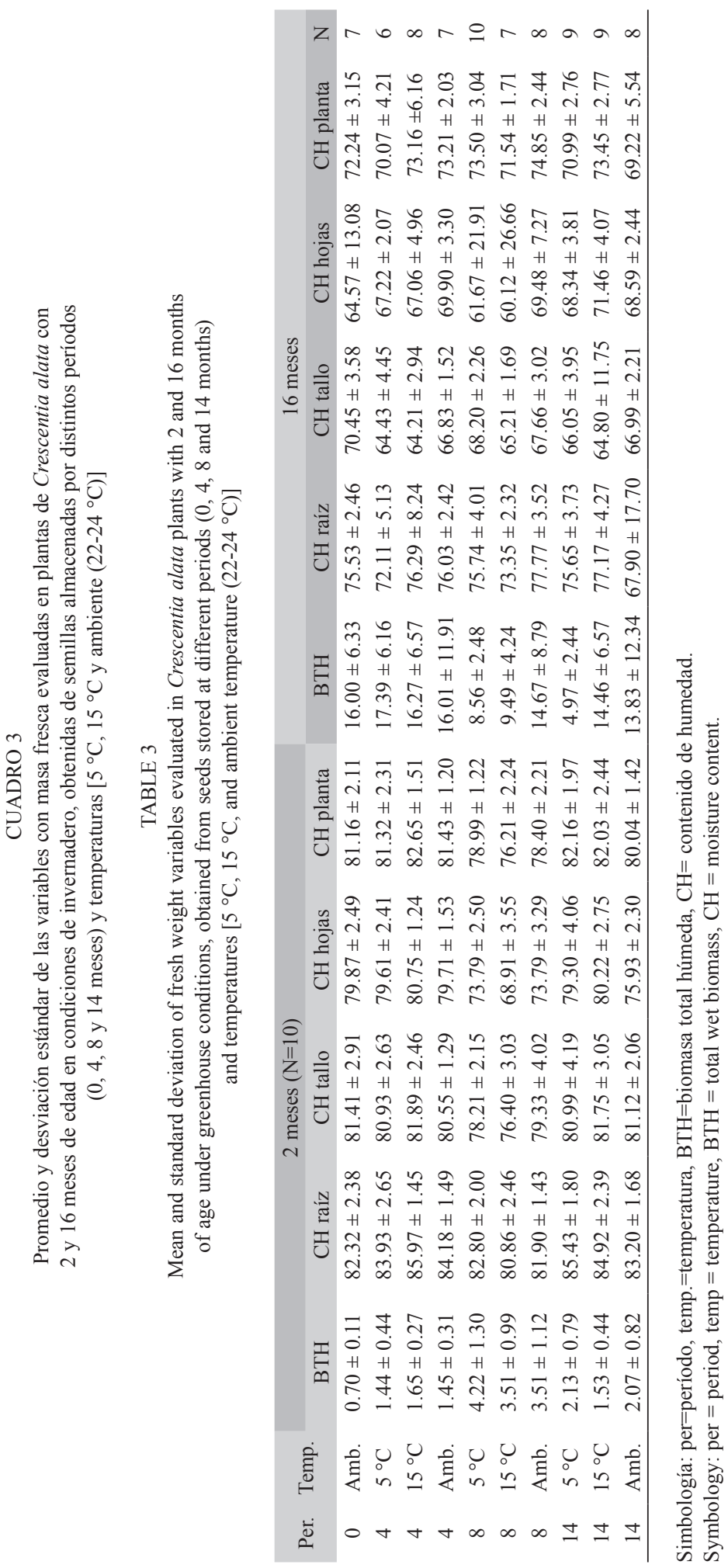
CUADRO 4

Promedio y desviación estándar de las tasas mensuales de crecimiento relativo (TCR), de elongación del tallo (TET) y de la raíz (TER) en plantas de Crescentia alata con 2 y 16 meses de edad, obtenidas de semillas almacenadas en distintos períodos y temperaturas

TABLE 4

Mean and standard deviation of monthly relative-growth rates (TCR), stem (TET) and root (TER) elongation in plants of Crescentia alata with 2 and 16 months of age, born from seeds stored at different periods and temperatures

\begin{tabular}{cccccc} 
Período & Temperatura & $\mathrm{N}$ & TCR $(\mathrm{cm} / \mathrm{mes})$ & TET $(\mathrm{cm} / \mathrm{mes})$ & TER $(\mathrm{cm} / \mathrm{mes})$ \\
0 & Ambiente & 7 & $1.09 \pm 0.45$ & $0.65 \pm 0.34$ & $1.91 \pm 1.15$ \\
4 & $5{ }^{\circ} \mathrm{C}$ & 6 & $1.12 \pm 0.43$ & $0.41 \pm 0.13$ & $0.95 \pm 0.88$ \\
4 & $15^{\circ} \mathrm{C}$ & 8 & $1.04 \pm 0.47$ & $0.22 \pm 0.30$ & $1.24 \pm 1.01$ \\
4 & Ambiente & 7 & $1.03 \pm 0.84$ & $0.32 \pm 0.34$ & $0.49 \pm 1.51$ \\
8 & $5^{\circ} \mathrm{C}$ & 10 & $0.31 \pm 0.18$ & $-0.17 \pm 0.37$ & $0.85 \pm 1.13$ \\
8 & $15^{\circ} \mathrm{C}$ & 7 & $0.43 \pm 0.28$ & $-0.20 \pm 0.26$ & $0.49 \pm 0.80$ \\
8 & Ambiente & 8 & $0.80 \pm 0.61$ & $0.43 \pm 0.32$ & $1.08 \pm 1.83$ \\
14 & $5{ }^{\circ} \mathrm{C}$ & 9 & $0.20 \pm 0.15$ & $0.25 \pm 0.17$ & $0.72 \pm 0.95$ \\
14 & $15^{\circ} \mathrm{C}$ & 9 & $0.92 \pm 0.47$ & $0.34 \pm 0.25$ & $1.09 \pm 0.73$ \\
14 & Ambiente & 8 & $0.84 \pm 0.88$ & $0.26 \pm 0.36$ & $0.90 \pm 0.77$ \\
\hline
\end{tabular}

$\mathrm{P}<0.001)$ (Tukey $=0.05$ ), y la TER fue mayor en 0 meses y difirió del resto $\left(\mathrm{F}_{5,87}=2.89, \mathrm{P}<\right.$ $0.02)($ Tukey $=0.05)$, de manera que las plantas de 0 meses crecieron más.

En la primera evaluación, plantas de dos meses mantuvieron adheridos ambos cotiledones verdes; además, la mayoría de raíces mostró protuberancias y estaban enrolladas sobre sí mismas, a pesar de tener suficiente espacio en la bolsa para crecer. En el ACP se eligieron dos componentes ( $\mathrm{C} 1$ y $\mathrm{C} 2$ ) (Cuadro 5 y 6); el $\mathrm{C} 1$ está dominado por la biomasa total seca (BTS) y biomasa seca (BS) en hojas, y el C2 por la BS en raíz-vástago, BS en tallo y BS en raíz (Fig. 2A). En el C1 hubo diferencias según el tiempo de almacenamiento $\left(\mathrm{F}_{2,81}=100.97\right.$, $\mathrm{P}<0.001)$, pero no según temperatura $\left(\mathrm{F}_{2,81}=\right.$ $1.49, \mathrm{P}=0.23)$ ni la interacción $\left(\mathrm{F}_{4,81}=1.92\right.$, $\mathrm{P}=0.11)$; se observaron diferencias entre 4,8 y 14 meses (Tukey $=0.05$ ). En el C2 no hubo diferencias según el tiempo de almacenamiento $\left(\mathrm{F}_{2,81}=0.67, \mathrm{P}=0.51\right)$, ni la temperatura $\left(\mathrm{F}_{2,81}\right.$ $=0.83, \mathrm{P}=0.44)$ ni la interacción $\left(\mathrm{F}_{4,81}=0.96\right.$, $\mathrm{P}=0.43$ ).

En la segunda evaluación, con 16 meses de edad, las plantas ya habían perdido los cotiledones. De 81 plantas evaluadas, 78 tenían la raíz enrollada en sí misma y 49 mostraban

\section{CUADRO 5}

Resultados de análisis de componentes principales en dos evaluaciones de plantas de Crescentia alata con 2 y 16 meses de edad en condiciones de invernadero

TABLE 5

Results of Principal Component Analysis in two evaluations of Crescentia alata plants with 2 and 16 months of age under greenhouse conditions

\begin{tabular}{lcccc} 
& ACP & Eigenvalue & Porcentaje & Porcentaje acumulado \\
2 meses & 1 & 4.16 & 46.26 & 46.26 \\
\multirow{3}{*}{16 meses } & 2 & 2.41 & 26.79 & 73.05 \\
& 1 & 3.57 & 39.71 & 39.71 \\
& 2 & 2.20 & 24.47 & 64.18 \\
& 3 & 1.29 & 14.32 & 78.50 \\
\hline
\end{tabular}




\section{CUADRO 6}

Resultados de autovectores ("eigenvectors") en el ACP de dos evaluaciones de plantas de Crescentia alata con 2 y 16 meses de edad en condiciones de invernadero

TABLE 6

Results of eigenvectors in a Principal Component Analysis of two evaluations of Crescentia alata plants with 2 and 16 months of age under greenhouse conditions

\begin{tabular}{|c|c|c|c|c|c|}
\hline & \multicolumn{2}{|c|}{2 meses } & \multicolumn{3}{|c|}{16 meses } \\
\hline & ACP 1 & $\mathrm{ACP} 2$ & ACP 1 & $\mathrm{ACP} 2$ & ACP 3 \\
\hline Longitud del vástago & 0.31 & 0.38 & -0.08 & 0.26 & $0.77 *$ \\
\hline Longitud de raíz & 0.29 & 0.10 & 0.35 & 0.16 & -0.13 \\
\hline Número de hojas & 0.34 & 0.31 & -0.03 & $0.60 *$ & 0.04 \\
\hline Área foliar & -0.36 & -0.14 & 0.10 & 0.27 & -0.25 \\
\hline Biomasa total seca & $0.43 *$ & 0.19 & 0.31 & 0.41 & 0.29 \\
\hline Biomasa en tallo & 0.03 & $0.45^{*}$ & -0.43 & -0.23 & 0.27 \\
\hline Biomasa en raíz & 0.34 & $-0.46^{*}$ & $0.50 *$ & -0.14 & 0.08 \\
\hline Biomasa en hojas & $-0.40 *$ & 0.23 & -0.27 & $0.45^{*}$ & $-0.40 *$ \\
\hline Relación raíz-vástago & 0.33 & $-0.47 *$ & $0.50 *$ & -0.17 & 0.03 \\
\hline
\end{tabular}

*Valores mayores en cada componente.

*Higher values in each component.
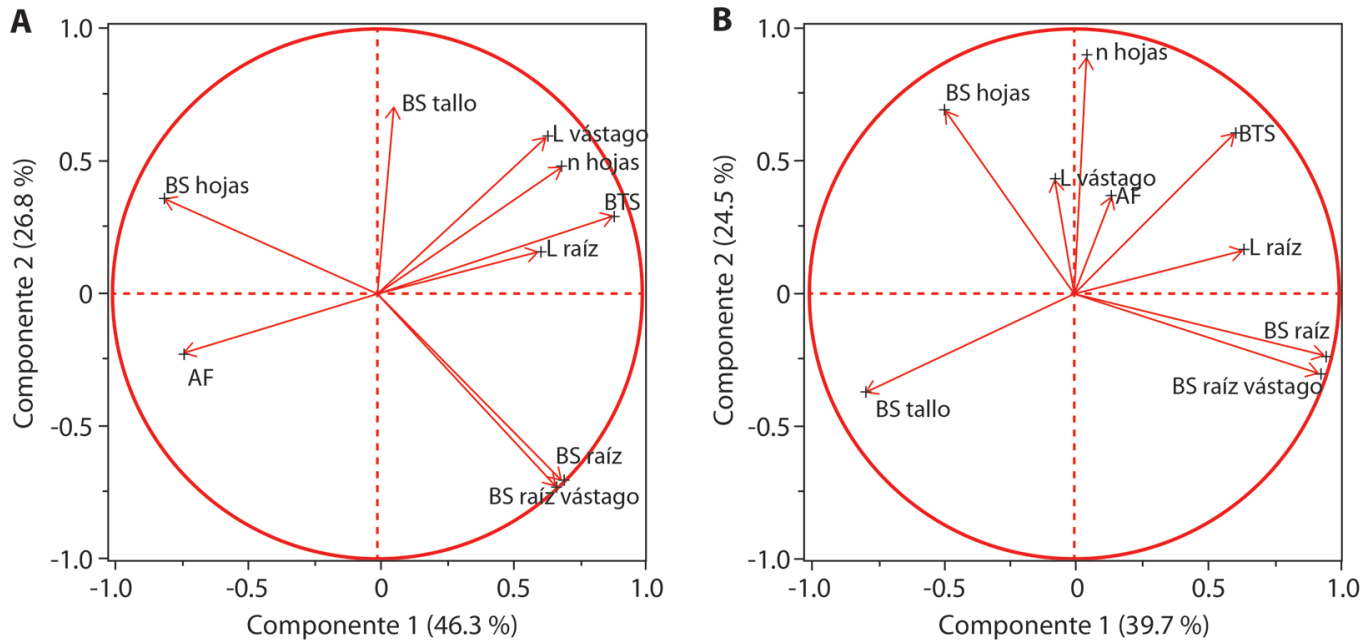

Fig. 2. Análisis de componentes principales de plantas de Crescentia alata en condiciones de invernadero con diferentes edades. A. evaluación de 2 meses; B. evaluación de 16 meses. Simbología: nhojas = número de hojas, AF = área foliar, Lraiz = longitud de raíz, Lvastago = longitud de vástago, BTS = biomasa total seca, BS hojas = biomasa seca asignada a hojas, $\mathrm{BS}$ tallo = biomasa seca asignada a tallo, BS raiz = biomasa seca asignada a raíz, BS raiz-vastago = relación de biomasa seca en raíz y vástago.

Fig. 2. Principal Component Analysis of Crescentia alata plants in greenhouse conditions with different ages. A. two-month evaluation; B. sixteen-month evaluation. Symbology: nhojas = leaf number, AF = leaf area, Lraiz = root length, Lvastago = shoot length, BTS = total dry biomass, BS hojas = dry biomass allocated to leaves, BS tallo = dry biomass allocated to stem, $\mathrm{BS}$ raiz $=$ dry biomass allocated to root, $\mathrm{BS}$ raiz-vastago $=$ dry biomass ratio in root and shoot. 
protuberancias radicales. En el análisis se eligieron tres componentes $(\mathrm{C} 1, \mathrm{C} 2, \mathrm{C} 3)$ (Cuadros 5 y 6); el $\mathrm{C} 1$ está dominado por $\mathrm{BS}$ en raíz y $\mathrm{BS}$ en raíz-vástago; el $\mathrm{C} 2$ por el número de hojas y la BS en hojas, y el C3 por la longitud del vástago y $\mathrm{BS}$ en hojas (Fig. 2B). En el C1 hubo diferencias según el tiempo de almacenamiento $\left(\mathrm{F}_{2,63}=13.54, \mathrm{P}<0.001\right)$, pero no según la temperatura $\left(\mathrm{F}_{2,63}=1.10, \mathrm{P}=0.34\right) \mathrm{ni}$ la interacción $\left(\mathrm{F}_{4,63}=0.88, \mathrm{P}=0.48\right)$; se notaron similitudes entre 4 y 8 meses, y estos tiempos son distintos a 14 meses (Tukey $=0.05)$. En el C2 hubo diferencias según el tiempo de almacenamiento $\left(\mathrm{F}_{2,63}=12.81, \mathrm{P}<0.001\right)$, pero no según la temperatura $\left(\mathrm{F}_{2,63}=1.93, \mathrm{P}=0.15\right)$ ni la interacción $\left(\mathrm{F}_{4,63}=1.82, \mathrm{P}=0.14\right)$; se notaron similitudes entre 4 y 14 meses, y estos tiempos son distintos a 8 meses (Tukey $=0.05$ ). En el C3 hubo diferencias según el tiempo de almacenamiento $\left(\mathrm{F}_{2,63}=4.11, \mathrm{P}=0.02\right)$, y la temperatura $\left(\mathrm{F}_{2,63}=3.17, \mathrm{P}=0.05\right)$, pero no en su interacción $\left(\mathrm{F}_{4,63}=2.41, \mathrm{P}=0.06\right)$. Las plantas obtenidas de semillas conservadas a temperatura ambiente son diferentes a las de 5 ${ }^{\circ} \mathrm{C}$ y $15{ }^{\circ} \mathrm{C}$ (Tukey $=0.05$ ), y las plantas obtenidas de semillas conservadas durante 4 meses difieren de las de 14 meses (Tukey $=0.05$ ).

El área foliar específica (AFE) no cambió con la temperatura de almacenaje $\left(\mathrm{F}_{2,87}=2.94\right.$, $\mathrm{P}<0.06)$. El AFE promedio ( \pm desviación estándar) fue de $226.97( \pm 72.00) \mathrm{cm}^{2} / \mathrm{g}$ a $5{ }^{\circ} \mathrm{C}$, $195.12( \pm 38.30) \mathrm{cm}^{2} / \mathrm{g}$ a $15{ }^{\circ} \mathrm{C}$ y $222.86( \pm$ $50.50) \mathrm{cm}^{2} / \mathrm{g}$ a temperatura ambiente.

Crecimiento según la luminosidad: En el experimento murieron cuatro plantas en la condición de sombra $(\mathrm{n}=6)$ y una planta en la condición de sol $(\mathrm{n}=9)$ ). Según los análisis de morfometría, en altura se encontraron diferencias según la luminosidad $\left(\mathrm{F}_{1,13}=8.10, \mathrm{P}\right.$ $=0.01$, Fig. $3 \mathrm{~A})$ y el tiempo $\left(\mathrm{F}_{9,5}=30.95, \mathrm{P}\right.$ $<0.001$ ), no así según luminosidad respecto al tiempo $\left(\mathrm{F}_{9,5}=2.07, \mathrm{P}=0.22\right)$. Respecto a diámetro se encontraron diferencias según la luminosidad $\left(\mathrm{F}_{1,13}=10.51, \mathrm{P}<0.01\right.$, Fig. 3B) y el tiempo $\left(\mathrm{F}_{9,5}=29.89, \mathrm{P}<0.001\right)$, también según luminosidad respecto al tiempo $\left(\mathrm{F}_{9,5}=\right.$ $32.88, \mathrm{P}<0.001)$. Con relación al número de hojas se encontraron diferencias según la luminosidad $\left(\mathrm{F}_{1,13}=5.80, \mathrm{P}=0.03\right.$, Fig. $\left.3 \mathrm{C}\right) \mathrm{y}$ el tiempo $\left(\mathrm{F}_{9,5}=76.50, \mathrm{P}<0.001\right)$, también según luminosidad respecto al tiempo $\left(\mathrm{F}_{9,5}=6.11, \mathrm{P}\right.$ $=0.03$ ). Las plantas más iluminadas mostraron tonalidades más intensamente verdes, pero en ambas condiciones los cotiledones se secaron a los 6 meses y permanecieron adheridos a las plantas hasta 14 meses.

\section{DISCUSIÓN}

Las semillas de Crescentia alata son longevas, porque después de almacenarlas 14 meses el porcentaje de germinación fue alto y la tasa de crecimiento de plantas fue buena. El deterioro de la calidad de la semilla durante el almacenamiento aumentó a temperaturas medias $\left(22-24{ }^{\circ} \mathrm{C}\right)$ y con mayor humedad. Al contrario, al disminuir el metabolismo de la semilla a bajas temperaturas y con menor contenido hídrico, aumenta el vigor (Salinas et al., 2001; Doria, 2010). Asimismo, la composición química de la semilla de cada especie influye en el vigor, como el contenido de ácidos grasos (Salinas et al., 2001). Los ácidos grasos actúan como antioxidantes e impiden la acción catabólica de los radicales libres en la membrana celular (Halliwell, 1990; Avello \& Suwalsky, 2006; Castaño, Valencia, Murillo, Méndez, \& Joli, 2012). Por tanto, un alto contenido de estos en la semilla protege del deterioro de las membranas celulares, preservando su calidad; esto podría explicar la resistencia de las semillas de C. alata ante largos períodos de almacenamiento, pues posee $38 \%$ de lípidos y cierto contenido de ácido fítico, que también actúa como antioxidante (Corrales et al., 2017).

Las semillas de Crescentia alata mantuvieron la viabilidad almacenadas durante tres años (Valverde-Rodríguez et al., 2019), pero el crecimiento de las plántulas varió según el tiempo de almacenaje. En ocasiones la longitud del hipocótilo se usa como indicador de crecimiento en las plántulas; así, en Coffea arabica L. (Rubiaceae) el hipocótilo crece menos si las semillas fueron previamente secadas a $40{ }^{\circ} \mathrm{C}$ o almacenadas a $20^{\circ} \mathrm{C}$; además, las semillas se 

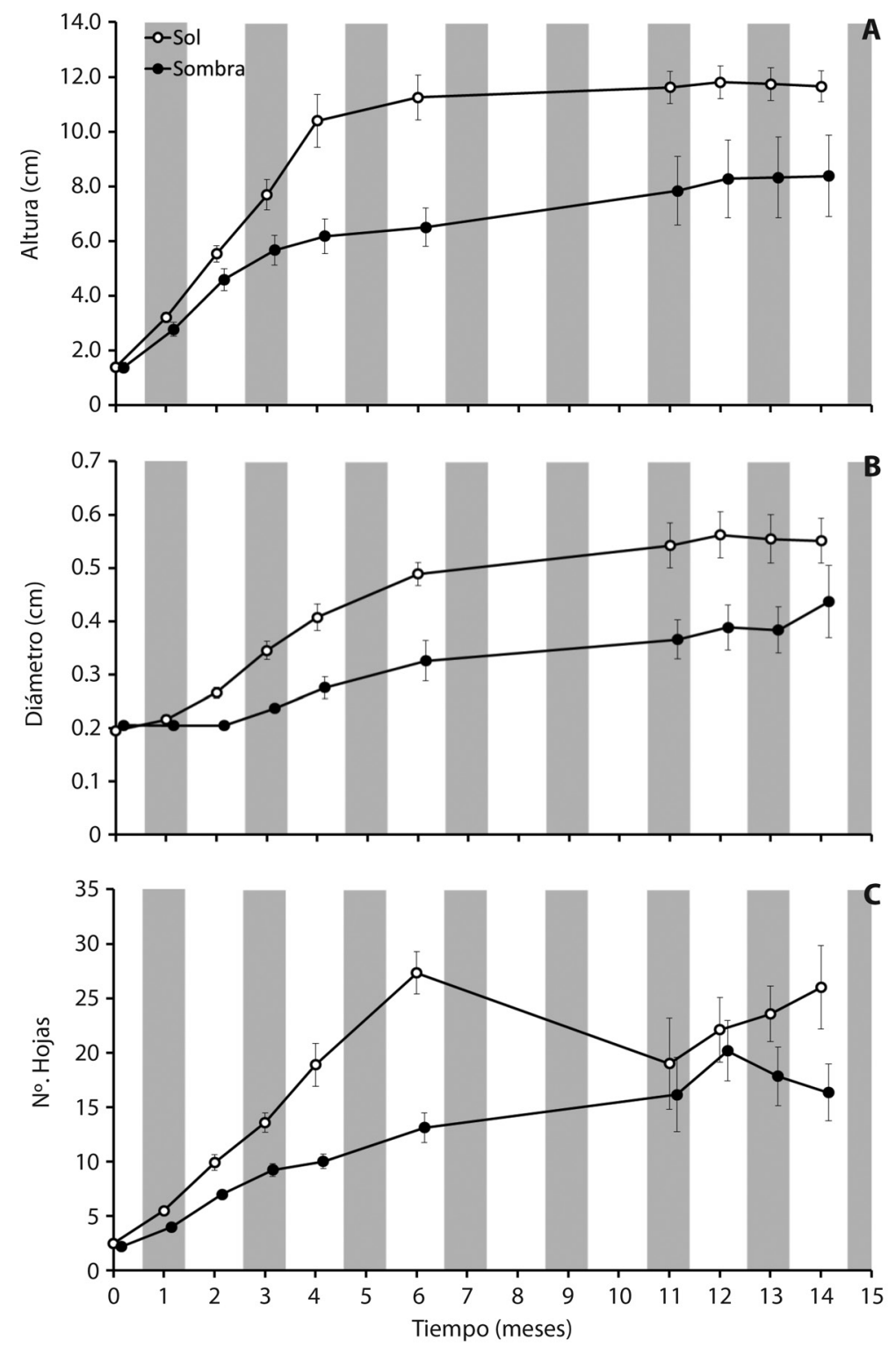

Fig. 3. Morfometría (promedios \pm error estándar) en plantas de Crescentia alata según luminosidad (sol y sombra) en condiciones de invernadero durante 14 meses en San José, Costa Rica. A. altura del tallo $(\mathrm{cm})$; B. diámetro del tallo $(\mathrm{cm})$; C. número de hojas.

Fig. 3. Morphometry (averages \pm standard error) in Crescentia alata plants related to luminosity (sun and shade) in greenhouse conditions during 14 months in San José, Costa Rica. A. stem height (cm); B. stem diameter (cm); C. leaf number. 
deterioran y germinan menos al preservarlas un año (Barboza \& Herrera, 1990). En plántulas de jícaro, a partir de semillas almacenadas 14 meses, la longitud del hipocótilo y el crecimiento del vástago se mantuvieron en valores promedio. Cuando esas semillas permanecieron a $5{ }^{\circ} \mathrm{C}$ ó $15{ }^{\circ} \mathrm{C}$, germinaron hasta $90 \%$, mientras que preservadas a temperatura ambiente se redujo la viabilidad de estos propágulos (Valverde-Rodríguez et al., 2019), pero no considerablemente el crecimiento de las plántulas.

La germinación y el contenido de humedad $(\mathrm{CH})$ de las semillas de C. alata (Valverde-Rodríguez et al., 2019) tuvieron relación directa y estas semillas toleraron bajos niveles de humedad. En próximos experimentos, se recomienda utilizar sacos de papel aluminio para controlar mejor el ambiente de almacenamiento (Salinas et al., 2001) y registrar si aumenta la longitud de la radícula con otros contenidos de humedad superiores (Barboza \& Herrera, 1990; Doria, 2010).

Las tasas de crecimiento relativo y de elongación de tallo y raíz (TCR, TET y TER, respectivamente) disminuyeron con el almacenamiento, principalmente por largos períodos, y las plantas crecieron mejor cuando se obtuvieron de semillas no almacenadas. Un estudio en una zona seca de Malawi registra plantas de C. alata de 3 meses de edad con biomasa seca de $7.9 \mathrm{~g}$ (Ngulube, 1989), mientras el presente estudio registra plantas de 2 meses con riego semanal y solo $0.13( \pm 0.02) \mathrm{g}$ de biomasa seca. El enrollamiento de la raíz podría ser una característica natural del crecimiento de esta especie; sin embargo, en el marco de nuestro estudio no podemos explicar satisfactoriamente esta observación. Sería interesante comparar el desarrollo de raíces en invernadero y en ambiente natural.

En la evaluación de plantas de dos meses, las procedentes de semillas conservadas 8 meses (a tres temperaturas) registraron mayor biomasa total, con altos valores de biomasa en raíz, pero no así en hojas ni tallo. Las plantas de 0 y 8 meses tuvieron muchas raíces, mientras que las plantas de los demás tratamientos asignaron los recursos a tallos. Las semillas que no fueron conservadas produjeron plantas con menor biomasa en tallos, por lo que la asignación de recursos fue mayor en raíces. También aquellas sembradas en meses calurosos, 0 meses en mayo y 8 meses en enero, desarrollaron más las raíces que tallos y hojas, lo que pudo ser una respuesta al suelo más seco y a mayor transpiración de las plantas por aumento de radiación solar en la época seca.

En la evaluación de 16 meses, las plantas procedentes de semillas almacenadas (a tres temperaturas) durante 4 y 8 meses mostraron las mayores biomasas de raíces, pero las de 14 meses registraron las menores. Con las semillas de C. alata conservadas durante 14 meses, las plantas resultantes tuvieron menor masa de raíces, aunque la longitud de raíz fue igual que en el resto de tratamientos. Las plantas de 8 meses mostraron la mayor biomasa en raíces y los valores menores en biomasa de hojas, número de hojas y longitud de tallo. Estas diferencias se pueden explicar por el período de siembra, pues el trasplante se hizo en época seca (febrero) y el resto en época lluviosa. El aumento de la luz produce cambios en las plantas, pues se asigna menor biomasa a hojas y mayor a raíces; de esta forma se mantiene constante la tasa de transpiración y puede abastecerse la mayor demanda de nutrientes requeridos para el crecimiento ante condiciones de mucha luz (Evans $\&$ Poorter, 2001). Además, es posible que una mayor intensidad lumínica, característica de la época seca, cause mayor evaporación del agua en el suelo y explique así las diferencias en la asignación de biomasa.

Las plantas con 3 meses de edad mostraron un diámetro de tallo de $0.34( \pm 0.05) \mathrm{cm}$ y una altura de $7.69( \pm 1.74) \mathrm{cm}$, mientras que el estudio en Malawi con plantas de la misma edad registró un diámetro de $0.39 \mathrm{~cm}$ y una altura de $18.9 \mathrm{~cm}$ (Ngulube, 1989). Las plantas con 16 meses de edad provenientes de semillas almacenadas 8 meses a $5{ }^{\circ} \mathrm{C}$ y $15{ }^{\circ} \mathrm{C}$ mostraron las menores longitudes de tallo, $11.88( \pm 3.33) \mathrm{cm}$ y $11.47( \pm 2.70) \mathrm{cm}$, respectivamente, mientras las no preservadas midieron $16.73( \pm$ 4.69) $\mathrm{cm}$; de este modo, el almacenamiento afectó la longitud del tallo, como en Coffea arabica, 
en la que la longitud de la planta disminuye al aumentar el tiempo de almacenamiento (Barboza \& Herrera, 1990). Además, de las semillas sin almacenaje se obtuvieron las plantas con el mayor número de hojas, mientras a partir de semillas almacenadas 4 y 8 meses disminuyó tanto el número como la biomasa de hojas. Según las condiciones de almacenamiento (tiempo y temperatura), se determinó que después de almacenar las semillas 8 ó 14 meses a 5 ${ }^{\circ} \mathrm{C}$ se obtuvieron plantas con tallos más cortos.

Durante el crecimiento, las plantas permanecieron en las mismas condiciones de invernadero y el AFE no fue afectada por el almacenamiento. Puesto que el índice de área foliar de una especie es un indicador de la capacidad de absorber la radiación (Muñoz, Espinosa, Cancino, \& Herrera, 2008) y $C$. alata habita en áreas con mayor radiación solar (Guanacaste) que en el lugar de estudio, sería recomendable estudiar el efecto de los cambios de luminosidad sobre el AFE en sitios con alta intensidad lumínica y con variaciones de luz. En general, los árboles en condiciones de menor luminosidad tienen mayor área foliar por unidad de masa seca de hojas para captar mayor cantidad de luz (Garnier, Shipley, Roumet, \& Laurent, 2001; Muñoz et al., 2008).

Las evaluaciones de 2 y 16 meses con 8 meses de almacenamiento respecto a niveles lumínicos indican que $C$. alata se adapta a la luminosidad por medio de la reasignación de biomasa a ciertas partes, por tanto influye en la morfometría de las plantas. Sin embargo, sería recomendable experimentar con niveles de luz más contrastantes, especialmente en el bosque tropical seco, donde la disponibilidad de agua y nutrientes en los suelos varía significativamente a lo largo del año (Hoffman, Franco, Moreira, \& Haridasan, 2005). En próximos estudios sería interesante medir la aclimatación según la reasignación de nutrientes (Evans \& Poorter, 2001), pues las plantas pueden aclimatarse al entorno lumínico al cambiar la biomasa asignada a cada estructura (raíces, tallos y hojas), debido a la importancia de la disponibilidad de luz para la fotosíntesis (Holt, 1995; Evans \& Poorter, 2001). También se recomienda evaluar distintas temperaturas de secado para las semillas, porque se sabe que en otras especies influyen en la capacidad germinativa, el porcentaje de germinación, la longitud del hipocótilo y de la radícula, y la masa seca de la plántula.

Los resultados de este estudio indican que la mayoría de variables morfométricas medidas en plantas de C. alata con 8 días de germinadas aumentan su valor si provienen de semillas almacenadas. En plantas de 16 meses de edad las tasas de crecimiento relativo de tallo y de raíz disminuyen al aumentar el tiempo de almacenamiento; además, cuando se siembran en la época seca asignan mayor biomasa a raíces que a tallo. Para establecer plantaciones se propone utilizar semillas recientes o, si se almacenan, que sea a bajas temperaturas (5 ${ }^{\circ} \mathrm{C}$ ó $15{ }^{\circ} \mathrm{C}$ ) y por menos de ocho meses. Esto podría mejorar el crecimiento de las plantas y, así, las plantaciones establecidas podrían abastecer las necesidades y evitar la explotación de las poblaciones silvestres.

Declaración de ética: los autores declaran que todos están de acuerdo con esta publicación y que han hecho aportes que justifican su autoría; que no hay conflicto de interés de ningún tipo; y que han cumplido con todos los requisitos y procedimientos éticos y legales pertinentes. Todas las fuentes de financiamiento se detallan plena y claramente en la sección de agradecimientos. El respectivo documento legal firmado se encuentra en los archivos de la revista.

\section{AGRADECIMIENTOS}

El estudio fue financiado por la Vicerrectoría de Investigación y la Escuela de Biología de la Universidad de Costa Rica. Expresamos nuestra gratitud al Centro para Investigaciones en Granos y Semillas, por facilitarnos instrumentos, y al Área de Conservación Guanacaste por el permiso de recolecta de frutos. Además, un enorme agradecimiento a Gerardo Ávalos, a Federico Bolaños y a Eduardo Chacón por la orientación en el análisis estadístico, y a Axel Retana Salazar ${ }^{\dagger}$ y Paul Hanson por la identificación de insectos. 


\section{RESUMEN}

En el bosque tropical seco, el árbol Crescentia alata (Bignoniaceae) es un recurso cultural y económico, pero han fracasado algunos intentos para establecer plantaciones, que podrían satisfacer la producción comercial y, así, evitar el impacto en las poblaciones naturales. Por tanto, existe la necesidad de generar información biológica sobre esta especie para obtener plantas en condiciones de invernaderos. El objetivo de este trabajo fue evaluar la tasa de crecimiento de plantas de $C$. alata obtenidas de semillas que se almacenaron en diferentes períodos y a varias temperaturas, y determinar el efecto de la intensidad de la luz sobre el crecimiento de las plántulas. Se recolectaron frutos en Liberia (Guanacaste, Costa Rica) y se almacenaron semillas por $0,4,8$ y 14 meses a $5{ }^{\circ} \mathrm{C}, 15{ }^{\circ} \mathrm{C}$ y a temperatura ambiente $\left(22-24^{\circ} \mathrm{C}\right)$. Las plántulas de las semillas almacenadas por $0,4,8$ y 14 meses se trasplantaron para evaluar el crecimiento después de 8 días, 2 y 16 meses, y en dos condiciones de luminosidad. La morfología de las plántulas de 8 días cambió según el tiempo de almacenamiento. El análisis de componentes principales de la evaluación de 2 meses indica que las variables más significativas fueron biomasa total seca, biomasa seca de hojas, de raíz-vástago, de tallo y de raíz, mientras que en el análisis de la evaluación de 16 meses tales variables fueron biomasa seca de raíz, de raíz-vástago y de hojas, también número de hojas y longitud del vástago. El área foliar específica de plantas con 16 meses de edad obtenidas de semillas almacenadas 14 meses no cambió con la temperatura de almacenamiento. Además, dos condiciones de luminosidad influyeron en la altura, el diámetro del tallo o el número de hojas. El almacenamiento de semillas a $5{ }^{\circ} \mathrm{C}$ y $15{ }^{\circ} \mathrm{C}$ favoreció el desarrollo de los cotiledones, así como la longitud de la raíz y del hipocótilo. Plantas de 2 meses obtenidas de 0 y 8 meses asignaron mayor biomasa a raíces que a tallos, mejorando así la absorción de agua. Plantas de 16 meses provenientes de semillas no almacenadas desarrollaron el mayor número de hojas, y aquellas de semillas de 8 meses a $5{ }^{\circ} \mathrm{C}$ y $15{ }^{\circ} \mathrm{C}$ mostraron tallos más cortos. Las semillas almacenadas hasta 14 meses se convirtieron en plantas bien desarrolladas. Se recomienda a futuros investigadores evaluar la viabilidad a diferentes temperaturas de secado de las semillas y en niveles de intensidad lumínica más contrastantes durante el crecimiento.

Palabras clave: Jícaro; asignación de biomasa; desarrollo de plántulas; viabilidad; vigor; almacenamiento de semillas; Costa Rica.

\section{REFERENCIAS}

Alfaro, E. A., Alvarado, A., \& Chaverri, A. (2001). Cambios edáficos asociados a tres etapas sucesionales de Bosque Tropical Seco en Guanacaste, Costa Rica. Agronomía Costarricense, 25(1), 7-20.
Avello, M., \& Suwalsky, M. (2006). Radicales libres, antioxidantes naturales y mecanismos de protección. Atenea, 494, 161-172.

Barboza, R., \& Herrera, J. (1990). El vigor en la semilla de café y su relación con la temperatura de secado, el contenido de humedad y las condiciones de almacenamiento. Agronomía Costarricense, 14(1), 1-8.

Castaño, D., Valencia, M. P., Murillo, E., Méndez, J. \& Joli, J. (2012). Fatty acid a composition of inca peanut (Plukenetia volubilis L.) and its relationship with vegetal bioactivity. Revista Chilena de Nutrición, $39,45-52$.

Cordero, J., \& Boshier, D. (2003). Árboles de Centroamérica: Un manual para extensionistas. Turrialba, Costa Rica: CATIE. Recuperado de http://orton.catie.ac.cr/ repdoc/a11445e/a11445e.pdf

Corrales, C. V., Fliedel, G., Perez, A. M., Servent, A., Prades, A., Dornier, M.,... \& Vaillant, F. (2017). Physicochemical characterization of jicaro seeds (Crescentia alata H.B.K.): A novel protein and oleaginous seed. Journal of Food Composition and Analysis, 56, 84-92.

De Viana, M. L., Mosiaro, M. J., \& Morandini, M. N. (2009). Tolerancia a la desecación de semillas de dos especies arbóreas del Chaco Salteño (Argentina): Erithryna falcata Benth. y Tecoma garrocha Hieron. Revista Cientifica Universidad de Oriente Agrícola, 9(3), 590-594.

Doria, J. (2010). Generalidades sobre las semillas: su producción, conservación y almacenamiento. Cultivos Tropicales, 31(1), 74-85.

Elias, T., \& Prance, G. (1978). Nectaries on the fruit of Crescentia and other Bignoniaceae. Brittonia, 30(2), 175-181. Recuperado de http://www.jstor.org/ stable/2806648

Evans, J. R., \& Poorter, H. (2001). Photosynthetic acclimation of plants to growth irradiance: the relative importance of specific leaf area and nitrogen partitioning in maximizing carbón gain. Plant, Cell and Environment, 24, 755-767.

Figueroa, S., \& Bressani, R. (2000). Recursos alimenticios vegetales con potencial de explotación agroindustrial de Guatemala: elaboración de leche vegetal a partir de la semilla del fruto de morro (Crescentia alata). Archivos Latinoamericanos de Nutrición, 50(2), 164-70.

Galindo-González, J. (1998). Dispersión de semillas por murciélagos: su importancia en la conservación y regeneración del bosque tropical. Acta Zoológica Mexicana, 73, 57-74.

Garnier, E., Shipley, B., Roumet, C., \& Laurent, G. (2001). A standardized protocol for the determination of 
specific leaf area and leaf dry matter content. Functional Ecology, 15, 688-695.

Gentry, A. H. (1980). Bignoniaceae: Part 1 (Crescentieae and Tourrettieae). Flora Neotropica, 25, 1-130.

González, E. (1991). Recolección y germinación de semillas de 26 especies arbóreas del bosque húmedo tropical. Revista de Biología Tropical, 39(1), 47-51.

Halliwell, B. (1990). How to characterize a biological antioxidant. Free Radical Research Communications, 9(1), 1-32.

Hoffman, W. A., Franco, A. C., Moreira, M. Z., \& Haridasan, M. (2005). Specific leaf area explains differences in leaf traits between congeneric savanna and forests trees. Functional Ecology, 19, 932-940.

Holt, J. S. (1995). Plant responses to light: a potential tool for weed management. Weed Science, 43(3), 474-482.

Hong, T. D., \& Ellis, R. H. (1996). A protocol to determine seed storage behaviour. IPGRI Technical Bulletin No. 1. International Plant Genetic Resources Institute, Roma. Recuperado de https://cropgenebank.sgrp. cgiar.org/ images/file/learning_space/ technicalbulletin1.pdf

ISTA (International Seed Testing Association). (2016). International rules for seed testing. Bassersdorf, Suiza. Recuperado de https:/www.seedtest.org/en/ home.html

Janzen, D. (1982). Fruit traits, and seed consumption by rodents, of Crescentia alata (Bignoniaceae) in Santa Rosa National Park, Costa Rica. American Journal of Botany, 69(8), 1258-1268.

Lambers, H., Chapin, F. S., \& Pons, T. L. (2008). Plant physiological ecology. Nueva York, Estados Unidos: Springer.

Mostacedo, B., Pereira, M., \& Fredericksen, T. (2001). Dispersión de semillas anemócoras y autócoras durante la época seca en áreas con aprovechamiento forestal en un bosque seco tropical. Ecología en Bolivia, 36, 3-16.

Muñoz, F., Espinosa, M., Cancino, J., \& Herrera, M. (2008). Efecto de la poda y raleo en el área foliar de Eucalyptus nitens. Bosque, 29(1), 44-51.

Navarro, M., Febles, G., \& Torres, V. (2012). Bases conceptuales para la estimación del vigor de las semillas a través de indicadores del crecimiento y el desarrollo inicial. Pastos y Forrajes, 35(3), 233-246.

Nellis, D. (1997). Poisonous plants \& animals of Florida and the Caribbean. Sarasota, Florida: Pineapple Press Inc.

Ngulube, M. R. (1989). Seed germination, seedling growth and biomass production of eight Central-American multipurpose trees under nursery conditions in Zomba, Malawi. Forest Ecology and Management, 27, 21-27.

Quesada-Monge, R., \& Fernández-Vega, J. (2005). Actualización de listado de especies arbóreas de uso forestal y otros usos en Costa Rica. Revista Forestal Mesoamericana Kurú, 2(4), 1-45.

R Development Core Team. (2014). R: A languaje and environment for statistical computing. Vienna, Austria. Recuperado de http://www.R-project.org

Salazar, R., \& Soihet, C. (2001). Manejo de semillas de 75 especies forestales de América Latina. Turrialba, Costa Rica: CATIE. Recuperado de http://orton.catie. ac.cr/ REPDOC/A4004E/A4004E.PDF

Salinas, A., Yoldjian, A., Craviotto, R., \& Bisaro, V. (2001). Pruebas de vigor y calidad fisiológica de semillas de soja. Pesquisa Agropecuária Brasileira, 36(2), 371-379.

SAS Institute Inc. (2012). JMP version 10.0.0. Cary, North Carolina: SAS Institute. Recuperado de http://www. jmp.com

Snarkis, M. (1989). Compendio de Agronomía Tropical. Instituto Interamericano de Cooperación para la Agricultura y Ministerio de Asuntos Extranjeros de Francia. San José, Costa Rica: IICA.

Solares, F. (2004). Etnobotánica y usos potenciales del Cirián (Crescentia alata, H.B.K.) en el Estado de Morelos. Polibotánica, 18, 13-31.

Standley, P. C. (1928). Flora of the Panama Canal Zone. (Contributions from the United States National Herbarium, 27). Washington, Estados Unidos. (Reimpreso 1968, Lehre, Alemania: Cramer).

Valverde-Rodríguez, K., Morales, C. O., \& García, E. (2019). Germinación de semillas de Crescentia alata (Bignoniaceae) en distintas condiciones de temperatura, luminosidad y almacenamiento. Revista de Biología Tropical, 67(2) Suplemento, S120-S131.

Vargas, G. (2011). Estudio cartográfico de los cambios de la vegetación de sabana en el Parque Nacional Santa Rosa, Guanacaste. Revista Geográfica, 47, 71-96.

Wyse, S. V., \& Dickie, J. B. (2018). Taxonomic affinity, habitat and seed mass strongly predict seed desiccation response: a boosted regression trees analysis based on 17539 species. Annals of Botany, 121, 71-83.

Zamora, S., García, J., Bonilla, G., Aguilar, H., Harvey, C. A., \& Ibrahim, M. (2001). ¿Cómo utilizar los frutos de guanacaste (Enterolobium cyclocarpum), guácimo (Guazuma ulmifolia), cenízaro (Pithecellobium saman) y jícaro (Crescentia alata) en alimentación animal? Agroforestería en las Américas, 8(31), 45-49. 


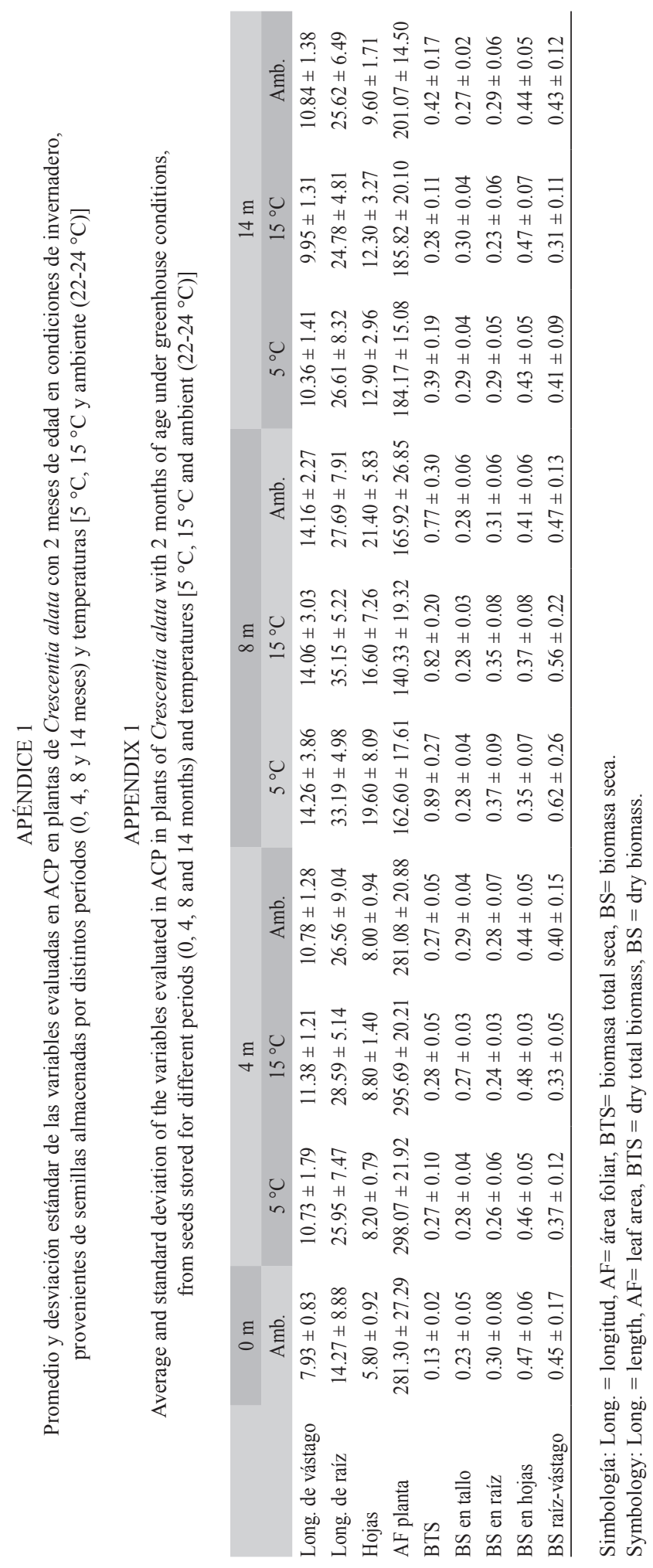



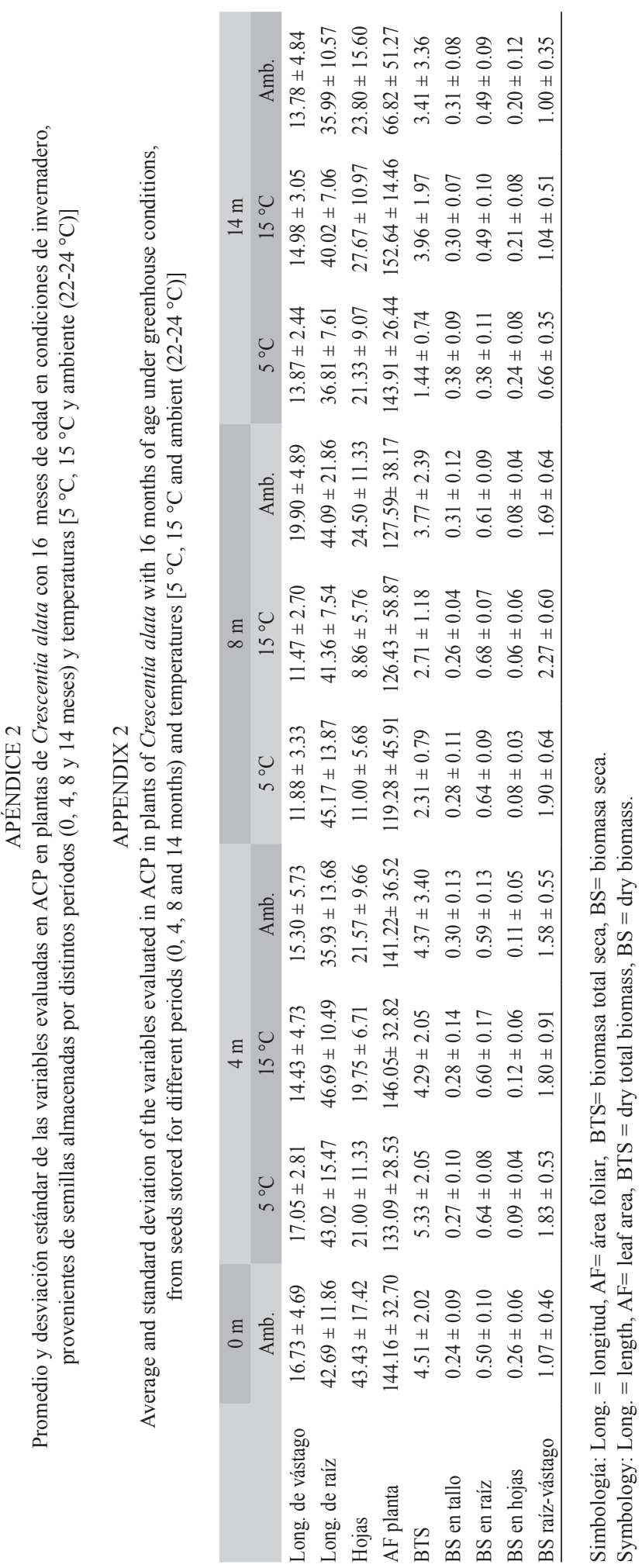